\title{
Breast Lesions during Pregnancy - a Diagnostic Challenge: Case Report
}

\author{
Ines Beyer Nikola Mutschler Katrin S. Blum Svjetlana Mohrmann \\ Department OB/GYN, University Hospital Duesseldorf, Germany
}

\section{Established Facts}

- Breast lesions often occur during pregnancy and are mostly benign in younger women, but the incidence of pregnancy-associated breast cancer is rising.

\section{Novel Insights}

- Complete surgical excision of the breast lesion is advised, even during pregnancy and the lactation period, to confirm the histology to prevent excessive treatment, e.g. treatment with tamoxifen in case of a ductal carcinoma in situ.

\section{Keywords}

Juvenile papillomatosis .

Pregnancy-associated breast lesions · Diagnosis

\section{Summary}

Background: Palpable masses of the breast often occur during pregnancy and should be further investigated. The standard diagnostic during pregnancy is an ultrasound combined, if needed, with a core needle biopsy. Most lesions are benign in younger women but, nevertheless, the incidence of pregnancy-associated breast cancer is 1 in 3,000 deliveries and rising. Case Report: We report the case of a 24-year-old patient diagnosed with a palpable breast lesion at 37 weeks of gestation. An ultrasound was performed and the lesion was rated BI-RADS 4. The initial core needle biopsy showed a ductal carcinoma in situ. After delivery and ablactating, a mammography, breast magnetic resonance imaging and a second ultrasound-guided biopsy was performed. Due to the inconclusive imaging and histological results, a wide excision was performed and a juvenile papillomatosis was confirmed. No further resection was necessary as the initial margins were sufficient. Conclusion: This case suggests that the diagnosis of masses of the breast during pregnancy and lactation can be quite difficult. Diagnosis should be confirmed by an excision biopsy and by histological examination through an experienced pathologist. As a significant proportion of papillomas contain malignant regions, an argument exists for the complete excision of all papillary tumours.

\section{Introduction}

Palpable masses of the breast often occur during pregnancy and lactation. Masses that remain longer than 2 weeks should be further investigated [1]. Due to changes in the breast during pregnancy, the

\begin{tabular}{ll}
\hline KARGER & $\oplus$ 2015 S. Karger GmbH, Freiburg \\
& $1661-3791 / 15 / 0103-0207 \$ 39.50 / 0$ \\
Fax +497614520714 & \\
$\begin{array}{l}\text { Information@Karger.com } \\
\text { www.karger.com }\end{array}$ & Accessible online at: \\
& www.karger.com/brc
\end{tabular}




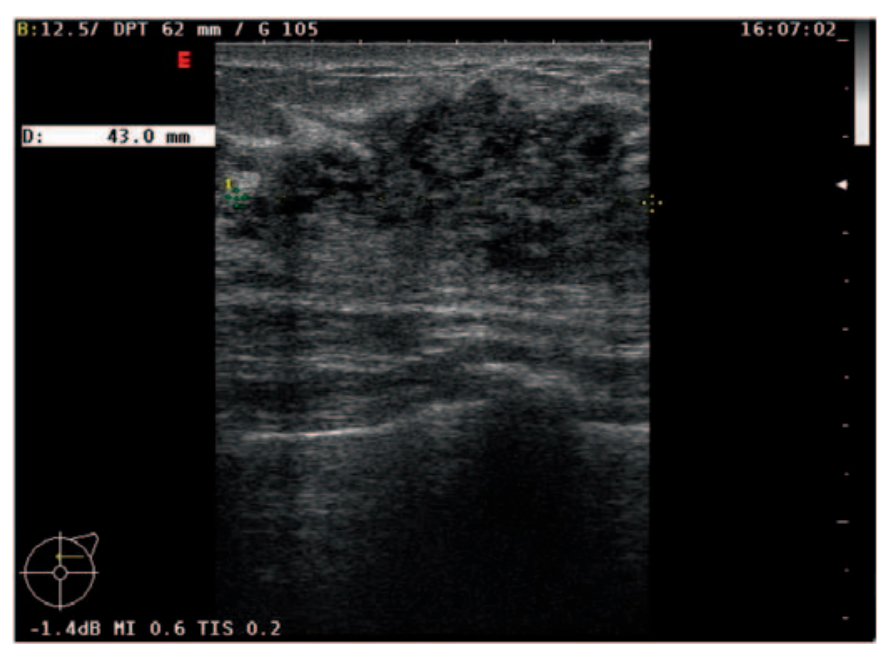

Fig. 1. An ultrasound image of the breast showing the maximal diameter of the breast tumour. The tumour is of irregular shape, inhomogeneous structure, with no clear borders and a complex echo density. Doppler sonography was not performed.

standard diagnostics may not show reliable results on normal breast tissue. Mammography is not particularly useful in pregnant and lactating women, due to a decreased sensitivity caused by the radiodense nature of the breast tissue. In addition, foetal radiation levels, even when performed with proper shielding of the foetus, may concern the mother $[2,3]$. Therefore, the standard diagnostic method during pregnancy is ultrasound, as there is no radiation exposure risk for the foetus and it can distinguish between benign and malignant processes. According to the German S3 guidelines, ultrasound can also be combined with a percutaneous core needle biopsy to confirm the nature of the mass in the case of a suspicious lesion [4]. As a biopsy has a very low rate of complications, it should be performed in all cases, even if the patient is still pregnant, to differentiate benign from malignant masses [5-7]. Most lesions in young women are benign; nevertheless, the incidence of pregnancy-associated breast cancer is 1 in 3,000 deliveries and accounts for approximately $1 \%$ of all breast cancers $[8,9]$. In addition, as women delay pregnancy past the age of 30 , the number of patients diagnosed with breast cancer during pregnancy increases [10]. With the following case report we show the diagnostic challenges associated with unclear breast lesions during pregnancy.

\section{Case Report}

We report here on a 24-year-old Gravida I Para 0 patient with years of known systemic lupus erythematosus. A mass of approximately $4 \mathrm{~cm}$ in diameter was detected in the left breast during the $37 \mathrm{th}$ week of gestation. The initial ultrasound showed a lesion of $20.1 \times 43 \times 28 \mathrm{~mm}$, corresponding to a score of 4 according to the Breast Imaging, Reporting and Data System (BI-RADS) analogue the DEGUM criteria (fig. 1) [11]. To determine the nature of the mass, a core needle biopsy and histological analysis were performed, leading to a diagnosis of ductal carcinoma in situ (DCIS). Although a DCIS is a pre-invasive lesion and can be associated with invasive carcinomas, further diagnostics were delayed until after the delivery of the full-term newborn. As the patient was diagnosed at the end of the third trimester, the patient insisted on a normal delivery

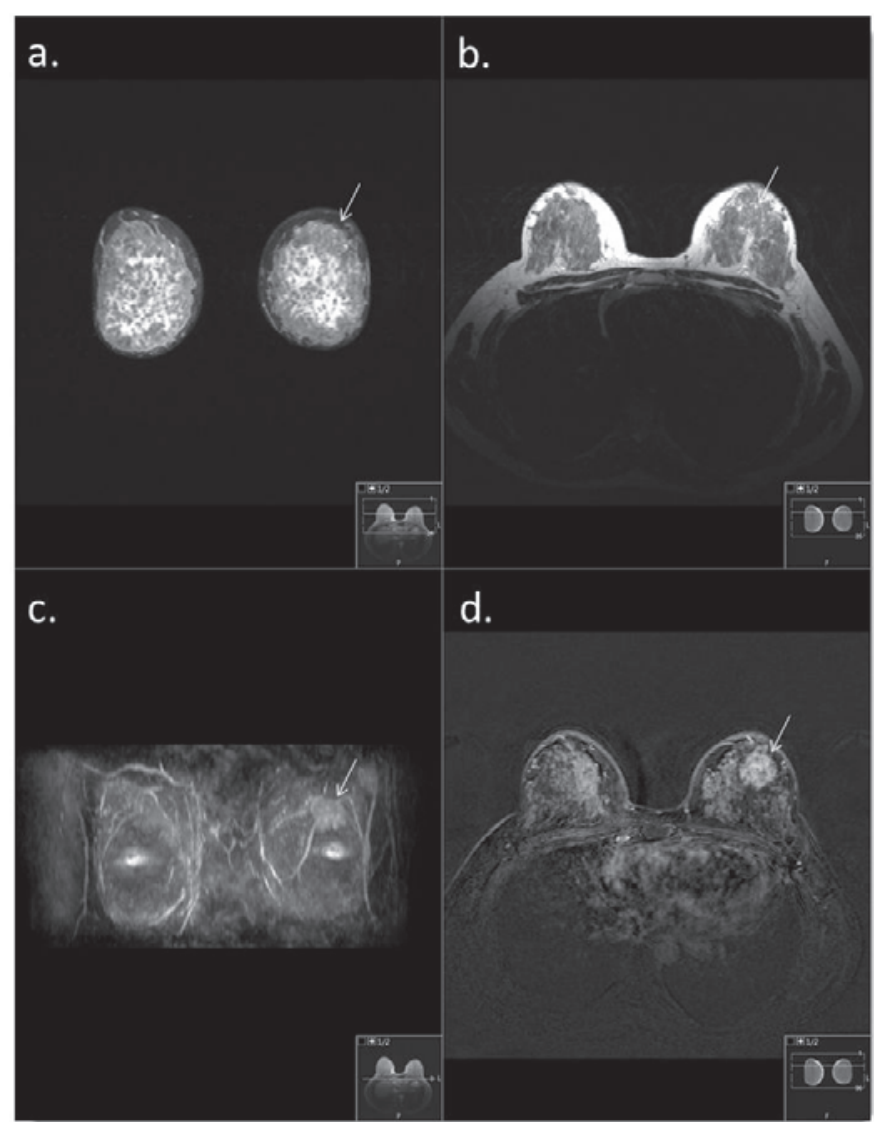

Fig. 2. A breast magnetic resonance image of the patient with the region of the tumour in the upper left breast indicated by the arrow. No clear mass is seen in the coronal STIR (a), or in the axial FSE T2-weighted image (b). Maximum intensity projection of subtracted T1-weighted images after intravenous contrast medium application shows a round enhancement in the upper part of the left breast (c), with a homogenous non-mass enhancement seen in the axial T1-weighted image (d).

at 40 weeks of gestation. Subsequent to primary ablactation postpartum, all diagnostic steps were performed or repeated, i.e. mammography, ultrasound, ultrasound-controlled core needle biopsy, and magnetic resonance imaging (MRI). The ultrasound result showed again a BI-RADS 4 lesion, while the mammography revealed a focal asymmetry on the left side with extremely dense breast tissue, American College of Radiology (ACR) category 4, and no sign of calcification (not shown). On MRI, a round lesion with non-mass enhancement was found, resembling a carcinoma, leading to an MRM BI-RADS 6 classification (fig. 2). Based on the preliminary evidence of a malignancy, a second core needle biopsy was performed on the clearest ultrasound-identified mass. The histological result showed a radial scar, which in approximately $30 \%$ of cases is associated with malignancy [12]. In addition, to gain a safe diagnosis of the lesion, a wide excision of the tumour was performed. The final report of the histology of the excised lump revealed a juvenile papillomatosis, which was confirmed by a second (external) pathologist. A further resection was not required as the initial resection margins were sufficient and an excellent cosmetic result was attained. As a risk for recurrent tumour development existed, the patient was advised to have a yearly follow-up, which so far has been unremarkable.

\section{Discussion}

Diagnosis of masses in the breast during pregnancy and lactation is considerably more difficult due to hormonal changes in the 
breast tissue that may obscure the mass and delay detection [2]. Changes in the breast tissue may include increased density, size and glandularity. Mammography can be performed during pregnancy with low foetal radiation exposure, but should be avoided. Moreover, the sensitivity of mammography is lower due to the enhanced density of the breast during pregnancy and lactation [13, 14]. In younger women, breast MRI is usually performed in addition to ultrasound but, as it requires the use of gadolinium as intravenous contrast medium, it should be restricted to non-pregnant women or only used with strong indication [14]. In the 'White Paper on Magnetic Resonance Safety', the American College of Radiology (ACR) recommends the use of MRI scans during pregnancy at any stage if the benefit of the MRI is higher than the risk to the mother and the foetus, and if the required information cannot be obtained by a different imaging method [15]. The main problem concerning a breast MRI during pregnancy is the high background enhancement of the parenchymal tissue, which also occurs during lactation and which may obscure pathologies [16, 17]. As the first trimester of pregnancy is the period of organogenesis, it is strongly advised that MRI is avoided during this formative stage of pregnancy [18].

Breast ultrasound is an attractive method in pregnant patients as it is safe for the foetus and sensitive in the detection of malignant breast lesions [19]. Hence, as ultrasound is the most effective method, it can be combined with colour Doppler ultrasound, which reveals the higher vascularity during pregnancy and even more so during lactation [20].

Despite reported complications, e.g. infections, allergy to local anaesthetic, haematoma formation and the development of milk fistula during pregnancy, core needle biopsy remains an established and safe procedure, regardless of the gestational period, and should therefore be used unequivocally to diagnose a breast mass $[6,7,21-23]$. This procedure is less invasive and stressful for the patient and has a very high sensitivity for the detection of malignant breast lesions. However, it is necessary that the pathologist is aware that the biopsy is from a pregnant patient as, due to hormonal influences, an epithelial proliferation in the lobular unit and an increased glandular vascularity will be observed [24]. In case of a disparity between the breast imaging and the histological results, biopsy should be repeated [14]. If this is not conclusive, the diag- nosis should be confirmed by an excision biopsy and an experienced pathologist should conduct the histological examination [25-27].

The presented patient was diagnosed with a form of ductal hyperplasia, juvenile papillomatosis; also known as 'Swiss cheese disease'. This is a rare but benign, proliferative tumour in young adolescent women. The histological changes associated with juvenile papillomatosis are considered premalignant in adults, and approximately $10 \%$ of patients have an associated breast carcinoma [28]. The general histological criteria for juvenile papillomatosis were defined by Rosen et al. (1985) as: duct papillomatosis with or without a degree of epithelial atypia, apocrine and non-apocrine cysts, papillary apocrine hyperplasia, sclerosing adenosis, and duct stasis [25]. For histological confirmation and prevention of recurrence, due to the uncertain prognosis, complete surgical excision and a yearly clinical follow-up is recommended [29]. To date, however, no link has actually been established between juvenile papillomatosis and pregnancy or lactation. Sabate et al. [30] reported a series of 18 patients with juvenile papillomatosis of which 5 were diagnosed during pregnancy. The microscopic findings, however, showed cystic and ductal hyperplasia with papillary hyperplasia [31].

In conclusion, a complete surgical excision of all papillary tumours is indicated, as a significant proportion of papillomas will contain foci of atypical or overt malignant regions, despite a sometime benign histological result of core biopsies [32]. If the mass is detected in the late third trimester the excision can be postponed until after delivery. It is, however, considered safe to perform a core needle biopsy and, if necessary, an excision, if the mass is detected during the first and second trimester [33]. When a segmental resection is performed, the other milk ducts can be spared and the patient retains the option of breastfeeding [34]. As the final histological result may differ from the initial biopsy, with regard to the cosmetic result, it might be beneficial to utilise closer surgical safety margins initially.

\section{Disclosure Statement}

All authors have declare no conflict of interest.

\section{References}

1 Loibl S, von Minckwitz G, Gwyn K, et al.: Breast carcinoma during pregnancy. Cancer 2006;106:237-246.

2 Nicklas AH, Baker ME: Imaging strategies in the pregnant breast cancer patient. Semin Oncol 2000;27:623632.

3 Brent RL: The effect of embryonic and fetal exposure to $\mathrm{x}$-ray, microwaves, and ultrasound: Counseling the pregnant and nonpregnant patient about these risks. Semin Oncol 1989;16:347-368.

4 Interdisziplinäre S3-Leitlinie für die Diagnostik, Therapie und Nachsorge des Mammakarzinoms, 2012, AWMF-Register-Nummer: 032-045OL.
5 Eedarapalli P, Jain S: Breast cancer in pregnancy. J Obstet Gynaecol 2006;26:1-4.

6 Liberman L, Kaplan JB, Morris EA, et al.: To excise or to sample the mammographic target: What is the goal of stereotactic 11-gauge vacuum-assisted breast biopsy? AJR Am J Roentgenol 2002;179:679-683.

7 Simon JR, Kalbhen CL, Cooper RA, Flisak ME: Accuracy and complication rates of US-guided vacuum-assisted core breast biopsy: Initial results. Radiology 2000;215:694-697.

8 Loibl S, Han SN, Amant F: Being pregnant and diagnosed with breast cancer. Breast Care 2012;7:204-209.
9 Loibl S, Han SN, von Minckwitz G, et al.: Treatment of breast cancer during pregnancy: An observational study. Lancet Oncol 2012;13:887-896.

10 Krishna I, Lindsay M: Breast cancer in pregnancy. Obstet Gynecol Clin North Am 2013;40:559-571.

11 Madjar H, Ohlinger R, Mundinger A, et al.: BI-RADSanalogue DEGUM criteria for findings in breast ultrasound-consensus of the DEGUM Committee on Breast Ultrasound. Ultraschall Med 2006;27:374-379.

12 Kennedy M, Masterson AV, Kerin M, Flanagan F: Pathology and clinical relevance of radial scars: A review. J Clin Pathol 2003;56:721-724. 
13 Nicklas AH, Baker ME: Imaging strategies in the pregnant breast cancer patient. Semin Oncol 2000;27:623632.

14 Litton JK, Theriault RL: Breast cancer and pregnancy: Current concepts in diagnosis and treatment. Oncologist 2010;15:1238-1247.

15 Kanal E, Borgstede JP, Barkovich AJ, et al.: American College of Radiology White Paper on MR Safety: 2004 update and revisions. AJR Am J Roentgenol 2004;182: 1111-1114

16 Talele AC, Slanetz PJ, Edmister WB, et al.: The lactating breast: MRI findings and literature review. Breast J. 2003;9:237-240.

17 Heywang-Kobrunner S, Schereer I, Dershaw D: Differential diagnosis and diagnostic work up and the young patient; in: Heywang-Kobrunner S, Schereer I, Dershaw D (eds): Diagnostic breast imaging: Mammography, sonography, magnetic resonance imaging and interventional procedures. New York, Thieme, 1997.

18 Leyendecker JR, Gorengaut V, Brown JJ: MR imaging of maternal diseases of the abdomen and pelvis during pregnancy and the immediate postpartum period. Radiographics 2004;24:1301-1316.

19 Kim SJ, Chang JM, Cho N, et al.: Outcome of breast lesions detected at screening ultrasonography. Eur J Radiol 2012;81:3229-3233.
20 Ahn BY, Kim HH, Moon WK, et al.: Pregnancy- and lactation-associated breast cancer: mammographic and sonographic findings. J Ultrasound Med 2003;22:491497.

21 Collins JC, Liao S, Wile AG: Surgical management of breast masses in pregnant women. J Reprod Med 1995; 40:785-788.

22 Kasprowicz N, Bauerschmitz GJ, Schönherr A, et al.: Recurrent mastitis after core needle biopsy: Case report of an unusual complication after core needle biopsy of a phyllodes tumor. Breast Care 2012;7:240-244.

23 Schackmuth EM, Harlow CL, Norton LW: Milk fistula: A complication after core breast biopsy. AJR Am J Roentgenol 1993;161:961-962.

24 Rosen PP: Anatomic and physiologic morphology; in Rosen PP (ed): Rosen's breast pathology, 2nd ed. Philadelphia, PA, Lippincott-Raven, 2001, pp 1-21.

25 Rosen PP, Holmes G, Lesser ML, et al.: Juvenile papillomatosis and breast carcinoma. Cancer 1985;55:13451352.

26 Ostrzega, N: Fine-needle aspiration cytology of juvenile papillomatosis of breast: A case report. Diagn Cytopathol 1993;9:457-460.
27 Ohlinger R, Schwesinger G, Schimming A, et al.: Juvenile papillomatosis (JP) of the female breast (Swiss Cheese Disease) - role of breast ultrasonography. Ultraschall Med 2005;26:42-45.

28 Gill J, Greenall M: Juvenile papillomatosis and breast cancer. J Surg Educ 2007;64:234-236.

29 Lad S, Seely J, Elmaadawi M, et al.: Juvenile papillomatosis: A case report and literature review. Clin Breast Cancer 2014;14:e103-105.

30 Sabate JM, Clotet M, Torrubia S, et al.: Radiologic evaluation of breast disorders related to pregnancy and lactation. Radiographics 2007;27(Suppl 1):S101-124.

31 Rosen PP: Breast tumors in children; in Rosen PP (ed): Rosen's breast pathology, 2nd ed. Philadelphia, PA, Lippincott-Raven, 2001, pp 729-748.

32 Brookes MJ, Bourke AG: Radiological appearances of papillary breast lesions. Clin Radiol 2008;63:1265-1273.

33 Dominici LS, Kuerer HM, Babiera G, et al.: Wound complications from surgery in pregnancy-associated breast cancer (PABC). Breast Dis 2010;31:1-5.

34 Gentilini O, Botteri E, Rotmensz N, et al.: Breast-conserving surgery in 201 very young patients ( $<35$ years). Breast 2010;19:55-58. 